\title{
13. Evaluating Low-Carbon City Development in China: Study of five national pilot cities ${ }^{1}$
}

\section{Biliang Hu, Jia Luo, Chunlai Chen and Bingqin Li}

\section{Introduction}

China was responsible for 25 per cent of global carbon dioxide emissions in 2012 (Liu 2015). This followed the passing of key milestones in the previous decade. From 2007, China's per capita carbon dioxide emissions exceeded the world average and it has become the world's largest contributor to annual carbon dioxide emissions, with the burning of fossil fuels and cement production being two important emission sources. According to World Bank research (Hu 2013), cities hold more than 65 per cent of global wealth, consume more than 65 per cent of global energy and emit some 70 per cent of greenhouse gases (GHGs). Reducing urban carbon dioxide emissions is considered to be key to reducing overall emissions, within which transforming cities into 'low-carbon cities' is seen as an important policy tool (Bao et al. 2008; Feliciano and Prosperi 2011).

China's urbanisation rate increased from 17.9 per cent in 1978 to 56.1 per cent in 2015. Under the Thirteenth Five-Year Plan (FYP), China's urbanisation rate is set to increase to 60 per cent by 2020. Fast economic growth and rapid development of urban centres have, however, already caused many environmental problems, including environmental degradation and air and water pollution, and this has drawn the increasing attention of the public (Li 2013; Gu et al. 2011). The pressure to reduce carbon dioxide emissions and so help achieve sustainable development is mounting both internationally and domestically.

In early 2008, the Ministry of Construction of China and the World Wide Fund for Nature (WWF) introduced the 'Low-Carbon City' pilot schemes in Shanghai and Baoding in Hebei province (near Beijing, and located in an area known as China's 'Power Valley'). In 2010, such schemes were formally endorsed by the National Development and Reform Commission (NDRC 2010). The main aims of

1 This chapter is part of the research arising from 'The Key Research Project of The National Social Science Fund of China on China New Urbanization: A five dimensional integration development approach' (14ZDA035). 
the pilot low-carbon city programs are to develop low-carbon dioxide emission industries, to establish a GHG emission data collection and management system and to encourage residents to adopt green and low-carbon consumption patterns and lifestyles. According to the NDRC document, this endorsement meant that five provinces (Guangdong, Liaoning, Hubei, Shanxi and Yunnan) and eight cities (Tianjin, Chongqing, Shenzhen, Xiamen, Hangzhou, Nanchang, Guiyang and Baoding) would enter the national low-carbon pilot scheme. A second batch of pilots entered the scheme in 2012, bringing to 36 the total number of cities involved (NDRC 2012).

One of the key challenges raised by observers of the pilot cities is that so far, despite strong public and government support and sound individual examples, no clear set of indicators exists to definitively measure the overall outcomes of low-carbon city projects ( $\mathrm{Hu}$ and $\mathrm{Li} 2016)$. This is not to say that specific initiatives are not important, as they may well contribute to the reduction of carbon dioxide emissions, but producing an overall evaluation of related projects in China could shed light on how low-carbon city initiatives have contributed to overall carbon dioxide emission levels.

This chapter develops a low-carbon city evaluation system to assess the performance of five pilot low-carbon city projects in China. Section two discusses and introduces the principles and the main indictors for evaluating the performance of low-carbon cities, including the methodology used herein. Section three uses the indicators to evaluate the performance of five national pilot low-carbon cities in China. The final section summarises the findings and provides policy suggestions based on our findings.

\section{Low-carbon cities in China}

Despite the number of low-carbon city pilots in China, there is no clear definition of what such a city is, with the implementation process also being used to shape the meaning of the concept for each city. As suggested in the name, the lowcarbon city initiative is meant to reduce the carbon dioxide emissions of cities. What complicates the endeavour is that Chinese cities vary greatly in their economic structure and environmental resources and their capacity to reduce carbon dioxide emissions. Cities therefore need to develop local strategies to fit their own circumstances (Li 2013). Introducing a universal standard for all cities to enforce would be unacceptable and could also suffocate local innovation.

As a result of these difficulties, the policy process is a two-way one: 1) the Central Government sets the overall target, as in the Twelfth FYP, to reduce the carbon intensity per unit of gross domestic product (GDP) by 17 per cent (Li and Wang 2012); and 2) local governments are held accountable for achieving the target. 
Local governments must come up with low-carbon development strategies to align with the aggregate target, which can be achieved by different means (Baeumler et al. 2012).

Given that China is urbanising rapidly, the intention is to reduce carbon dioxide emissions not in absolute terms, but in relative terms - that is, to combine economic development with carbon dioxide emission goals. In the low-carbon city initiatives, cities focus on cutting their carbon intensity (carbon dioxide emissions per unit of GDP) (Huang 2011) and adopt strategies to highlight their own advantages. The volume of carbon emissions, therefore, is used only as a reference.

To some extent, the pilots can be perceived as a form of field research. Through the practices of each city, policymakers can collect firsthand information on the effectiveness of a range of local strategies. However, such an approach also faces a challenge: how to assess the actual performance of cities carrying out various experiments. This chapter tries to address this challenge by designing a method by which to measure the performance of low-carbon cities.

\section{Evaluation of the performance of low-carbon cities}

To evaluate the performance of low-carbon cities, it is important to have a set of measureable indicators. This is a challenge both for China and for the rest of the world. The existing evaluation practices follow two approaches. One is to use a single indicator - for example, total carbon dioxide emissions, per capita carbon dioxide emissions, per capita residential consumption carbon dioxide emissions, per unit of land carbon dioxide emissions, carbon dioxide emissions intensity or the growth rate of carbon dioxide emissions. The advantage of this method is that it is clear and straightforward. It targets carbon dioxide emissions directly. However, even if it can be viewed as a composite indicator, this approach has been criticised for oversimplification and the risk of narrowing understanding of the issues (Weidema et al. 2008; Pulselli et al. 2015). Further, low-carbon cities are not just about lowering carbon dioxide emissions. More importantly, the concept also embraces sustainable development, which tries to strike a balance between economic development, environmental protection and efficient use of natural resources and energy.

The second, and more popular, approach to evaluating low-carbon cities is to create a set of indicators. This approach captures multiple dimensions of the performance of a low-carbon city and thus takes a broader approach than the first one. This approach can therefore also reflect the level of sustainable development of a low-carbon city. One such popular model is the Driving 
Force-Pressure-State-Impact-Response (DPSIR) model (Carr et al. 2007), which classifies economic, social, resource and environmental indicators into five categories: driving forces, pressure, state, impact and response. The advantage of this model is that it reveals the reciprocal relationship between the environment and economic activity, and also provides feedback via the status of resources and the environment on the potential impacts of human activities (Shao and Ju 2010; Wang 2013). To achieve this, the selection of indicators should be comprehensive. Examples include economic factors, such as per capita GDP, and demographic factors, such as population growth rate and the rate of urbanisation. The multivariate context makes it difficult to isolate drivers, not to mention generating targeted policies. Given that we want to produce targeted policy suggestions, we opt not to use DPSIR for our analyses.

Another popular approach is the Stochastic Impact by Regression on Population, Affluence and Technology (STIRPAT) model (York et al. 2003; Fan et al. 2006; Gabrielsen and Bosch 2003), which is developed from the Impact, Population, Affluence and Technology (IPAT) model. There are modified versions of the basic STIRPAT framework with which to evaluate the levels of low-carbon city development. These indicators take into account economic, social, environmental, resources and energy, technology and residential consumption. In this chapter, we adapt the STIRPAT model to analyse the performance of lowcarbon cities in China.

\section{The low-carbon city development index: Indicator selection}

Our evaluation framework includes five low-carbon city dimensions: economic growth, energy consumption, urban construction, government support and residential consumption. Seventeen specific indicators are selected based on the STIRPAT model. Our choice is adapted according to the China green development index report 2012, produced by the School of Economics and Resource Management of Beijing Normal University (Li and Pan 2015). This is widely regarded in China as the seminal annual report in this field. Figure 13.1 illustrates the evaluation framework, the five indicators and sub-indicators, on which we elaborate next. 


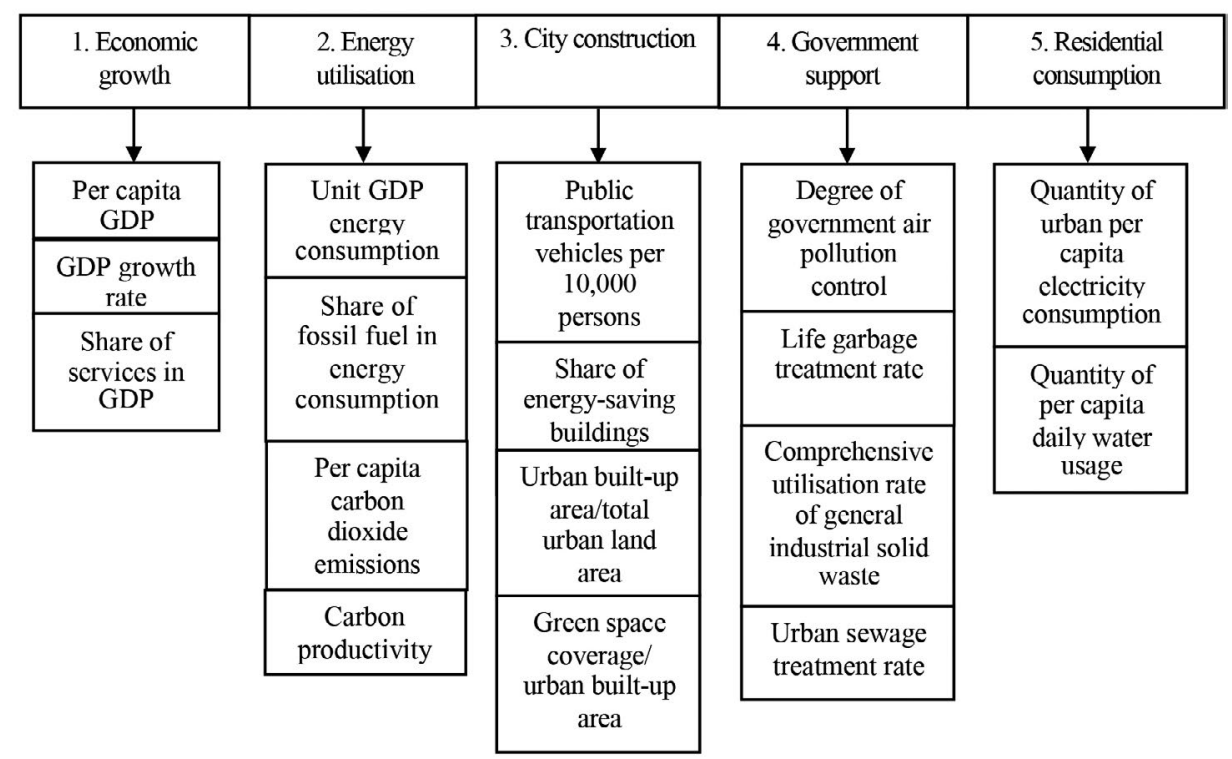

Figure 13.1 An indicator for the performance of cities in the 'low-carbon city' program

Source: Authors' own design.

Figure 13.1 shows the framework we use to measure five different aspects of performance. A composite indicator is calculated according to the performance of each city indicator. The composite indicator thus offers an overall assessment. For example, a city may have achieved a high level of economic growth; however, this outcome might be compromised by its poorer performance in terms of energy consumption.

With regard to the first indicator, economic growth, existing research shows that three economic factors are related to carbon dioxide emissions: the level of economic development (Selden and Song 1994; Stern and Common 2001), the rate of economic growth (Soytas and Sari 2009; Zhang and Cheng 2009) and the share of the services sector (Golove and Schipper 1997; Casler and Blair 1997). We selected three proxy indicators for these three economic factors: 1) GDP per capita - the level of economic development; 2) GDP growth rateeconomic growth; and 3) the services sector's share of GDP in total GDPeconomic structure.

The second indicator, energy utilisation, includes indicators for both energy consumption and carbon dioxide emissions. We choose unit GDP energy consumption and fossil fuels' share of energy consumption to measure energy consumption. Unit GDP energy consumption is measured as the total quantity of energy consumption divided by GDP. The higher the value of this 
indicator, the more energy will be used to produce a unit of GDP, thus having a negative impact on low-carbon city development. Fossil fuels' share of energy consumption is measured as the quantity of fossil fuels consumed divided by the total quantity of energy consumed. Because fossil fuels produce large carbon dioxide emissions, we consider that a high share of fossil fuels in total energy consumption will compromise the city's overall performance.

To capture total carbon dioxide emissions, we use the quantity of carbon dioxide emissions generated by industrial enterprises' energy consumption as the total quantity of a city's carbon dioxide emissions. We select two measures of carbon dioxide emissions. The first is per capita carbon dioxide emissions, measured as the total quantity of carbon dioxide emissions divided by the total population of a city, which subtracts from the level of low-carbon city development. The second measure is carbon productivity, measured as GDP divided by the total quantity of carbon dioxide emissions, which associates positively with the level of low-carbon city development. To measure carbon dioxide emissions, we include in our analyses coal, charcoal, four fuel products (petrol, kerosene, diesel and oil) and natural gas. We first convert the quantity of each type of energy into tonnes of standard coal equivalent (tce) and then multiply the quantity of tce by the carbon dioxide emissions index to generate the quantity of carbon dioxide emissions (see Table 13.1).

Table 13.1 Standard coal equivalent conversion index and carbon dioxide emissions index of energy categories

\begin{tabular}{|l|r|r|}
\hline Energy categories & $\begin{array}{r}\text { Standard coal equivalent } \\
\text { conversion index (tce/tonne) }\end{array}$ & $\begin{array}{r}\text { Carbon dioxide emissions index } \\
\text { (carbon dioxide tonne/tce) }\end{array}$ \\
\hline Coal & 0.71 & 0.76 \\
\hline Charcoal & 0.97 & 0.86 \\
\hline Petrol & 1.47 & 0.55 \\
\hline Kerosene & 1.47 & 0.57 \\
\hline Diesel & 1.46 & 0.59 \\
\hline Burning oil & 1.43 & 0.62 \\
\hline Natural gas & 1.27 & 0.45 \\
\hline
\end{tabular}

Sources: Standard coal conversion index is from NDRC (2008); IPCC (2006).

The third indicator, urban construction, includes four sub-indicators: 1) the number of public transportation vehicles per 10,000 people as a proxy for the coverage of public transportation; 2) the share of energy-saving buildings; 3 ) the green coverage rate of built-up areas, which represents the urban construction aspect and is positively associated with the level of low-carbon city development; and 4) the share of built-up areas in total urban land area. Poor performance in these indicators means that the overall performance is compromised. 
The fourth indicator, government support, is important because it reflects the fact that low-carbon city development is more difficult to achieve without active government support. It is included as a dimension for evaluation to stress the important role government can play in developing low-carbon cities, and to reflect the effect of government actions on city environmental controls. We choose four sub-indicators for this dimension: the degree of government air pollution control (measured as the number of days with air quality above grade two); the life garbage treatment rate; the comprehensive utilisation rate of general industrial solid waste; and the urban sewage treatment rate. When a city performs well in these four sub-indicators, this should also contribute positively to its overall performance.

The fifth indicator in our study, residential consumption, is captured by two subindicators: urban per capita electricity consumption and urban per capita daily water usage. These two sub-indicators contribute negatively to the indicator.

\section{Allocating weights}

There are two leading methods for assigning weights to selected indicators: subjective allocation and objective calculation. In this study, we adopt the subjective allocation approach. We invited 10 experts $^{2}$ with outstanding research achievements in this area to allocate weight to each indicator. Based on the resulting scores, the weight for economic growth is 20 per cent, 31 per cent for energy utilisation, 21 per cent for urban construction, 19 per cent for government support and 9 per cent for residential consumption. The details of weight allocations are presented in Table 13.2.

2 We would like to thank Professor Xiaoxi Li, Professor Weibin Lin, Professor Yongsheng Lin and Professor Yanting Zheng from Beijing Normal University; Professor Faqi Shi from the National Bureau of Statistics; Professor Zuojun Li from the Development Research Centre of the State Council; Professor Yulong Shi and Professor Changyun Jiang from the Macroeconomic Academy of the State Development and Reform Commission; and Professor Zhixiong Du and Professor Yuanhong Zhang from the Chinese Academy of Social Sciences, for their help in allocating weight to each of the indicators. 


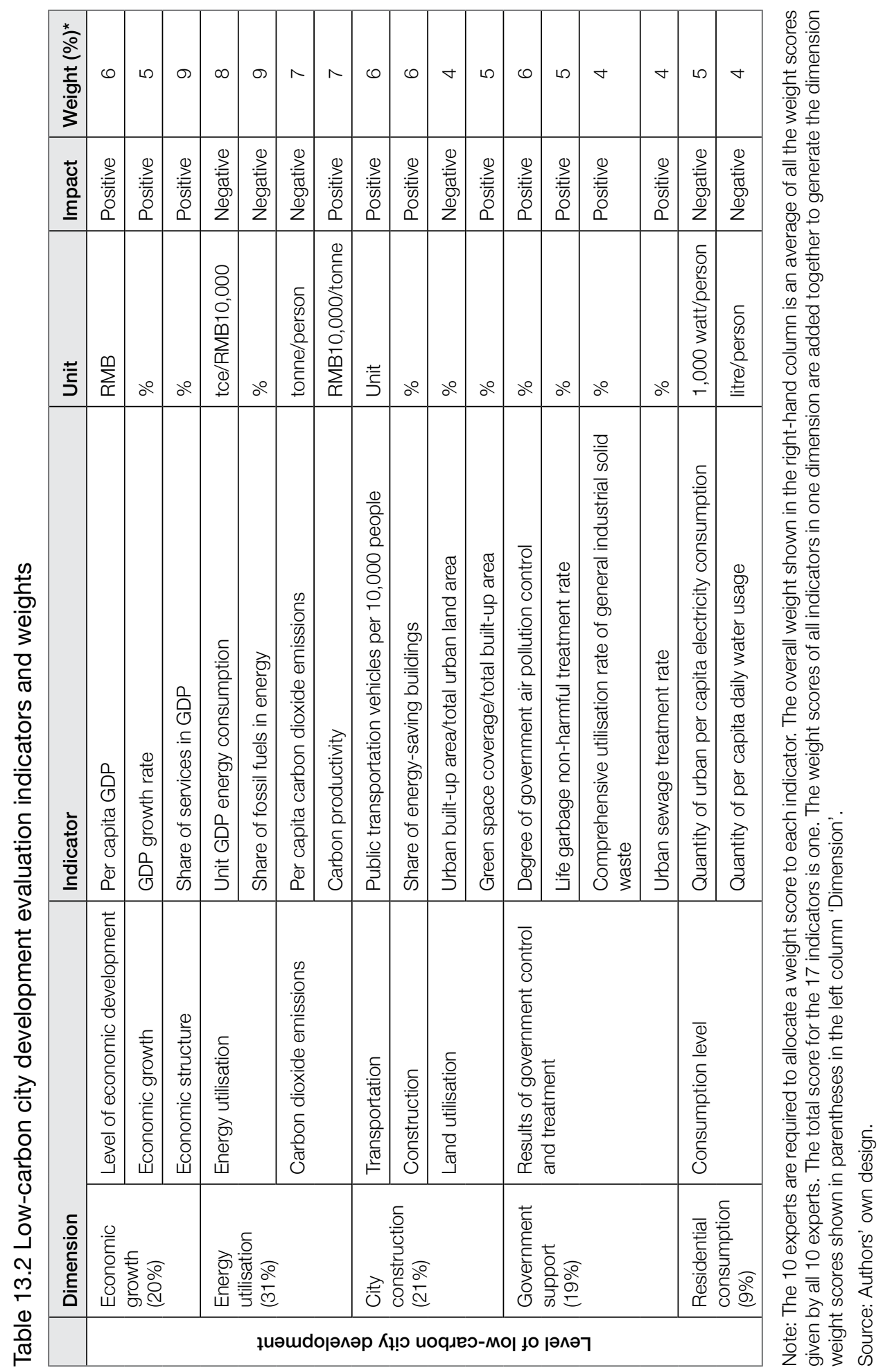




\section{Calculating the index}

Because different indicators are measured in different units, when calculating the low-carbon city development index (LCCDI), our first step is to use the following equations to calculate the standard value for all indicators.

Equation 13.1

$$
A^{\prime}=\frac{A-\operatorname{Min} A}{\operatorname{Max} A-\operatorname{Min} A}
$$

Equation 13.2

$$
A^{\prime}=\frac{\operatorname{Max} A-A}{\operatorname{Max} A-\operatorname{Min} A}
$$

In Equations 13.1 and 13.2, $A^{\prime}$ is the standard value, $A$ is the original value, MaxA is the maximum value and MinA is the minimum value of an indicator. The standard value of $A^{\prime}$ ranges from zero to one. Equation 13.1 is for the positive indicators and Equation 13.2 is for the negative indicators.

Second, based on the results from the above equations, we can use Equation 13.3 to calculate the score for each of the five dimensions and the total score of the LCCDI for a city.

\section{Equation 13.3}

$$
L C C D I=\sum_{i}^{n} w_{i} \times A^{\prime}
$$

In Equation 13.3, $w_{i}$ is the weight of indicator $i$. Based on the score calculated from Equation 13.3, we can compare the levels of low-carbon development for each city. The higher the value of the index, the higher is the level of lowcarbon development.

\section{Evaluating low-carbon city development}

For this study, we select five cities-Tianjin, Shenzhen, Hangzhou, Nanchang and Baoding - from the national pilot low-carbon city program. Shenzhen is a special economic zone, which still had a basic agrarian economy in the 1980s, but is today host to high and new technology industries, financial services and modern logistics and cultural industries. Hangzhou is in one of China's richest per capita provinces, Zhejiang, and is a famous tourist city. Its high and new technology industries are growing rapidly. Baoding, in contrast, is a 
less-developed, historical city in northern China. The city is increasingly host to heavy industries being relocated from Beijing and Tianjin. As a result, it is one of the most polluted cities in China. The rate of growth of Nanchang, in Jiangxi Province, has picked up in recent years and it is considered to have great potential for future development. Table 13.3 shows the basic information for the five selected cities.

Table 13.3 Basic information for the selected five cities, 2013

\begin{tabular}{|l|r|r|r|r|r|}
\hline City & \multicolumn{1}{|c|}{$\begin{array}{c}\text { Per capita } \\
\text { GDP } \\
\text { (RMB10,000) }\end{array}$} & $\begin{array}{c}\text { Land area } \\
\mathbf{( 1 0 , 0 0 0} \\
\text { sq } \mathbf{~ k m )}\end{array}$ & \multicolumn{1}{c|}{$\begin{array}{c}\text { Urbanisation } \\
\text { rate (\%) }\end{array}$} & $\begin{array}{c}\text { Unit GDP energy } \\
\text { consumption } \\
\text { tce/RMB10,000) }\end{array}$ & $\begin{array}{c}\text { Green coverage } \\
\text { rate of built-up } \\
\text { areas (\%) }\end{array}$ \\
\hline Tianjin & 9.96 & 1.19 & 82.01 & 0.64 & 34.93 \\
\hline Shenzhen & 13.69 & 0.20 & 100.00 & 0.48 & 45.07 \\
\hline Hangzhou & 9.46 & 1.66 & 74.90 & 0.56 & 40.23 \\
\hline Nanchang & 6.47 & 0.74 & 69.83 & 0.60 & 42.41 \\
\hline Baoding & 2.55 & 2.22 & 42.93 & 0.25 & 40.36 \\
\hline
\end{tabular}

Sources: NBS (2014b, 2014f); Statistics Bureau of Shenzhen City (2014); Tianjin Municipal Statistics Bureau (2014); Nanchang Municipal Statistics Bureau (2014); Statistical Bureau of Baoding (2014).

Based on the LCCDI outlined in section two, we calculated the level of lowcarbon city development for the eight national pilot low-carbon cities designated by the NDRC in 2010. Here we first evaluate the total level of lowcarbon city development and then the level of each dimension of low-carbon city development for the five selected representative cities.

\section{Evaluating the overall level of low-carbon city development}

The low-carbon city development indices for the five selected cities for the period 2010-13 are presented in Table 13.4.

As Table 13.4 shows, during the period 2010-13, the average LCCDI score for Shenzhen was 0.71 - the highest among the five cities. Hangzhou ranked second, with a score of 0.51 , followed by Nanchang (0.49), Tianjin (0.49) and Baoding (0.41). However, because the level of low-carbon development for Shenzhen is far higher than that for the other four cities, it raised the average level of low-carbon development and, as a result, the levels of low-carbon development for the other four cities are all below the average. It is important to note that even in Hangzhou, a world-famous tourist city, low-carbon development is at a relatively low level. Moreover, many Chinese cities have even lower levels of lowcarbon development, which suggests there is plenty of room for improvement for China's overall levels of low-carbon city development. 
Table 13.4 LCCDI and ranking of the five selected cities

\begin{tabular}{|c|c|c|c|c|c|c|c|c|c|c|}
\hline \multirow[b]{2}{*}{ City } & \multicolumn{2}{|c|}{$\begin{array}{c}\text { Four-year } \\
\text { average }\end{array}$} & \multicolumn{2}{|c|}{2010} & \multicolumn{2}{|c|}{2011} & \multicolumn{2}{|c|}{2012} & \multicolumn{2}{|c|}{2013} \\
\hline & Score & Ranking & Score & Ranking & Score & Ranking & Score & Ranking & Score & Ranking \\
\hline Shenzhen & 0.71 & 1 & 0.75 & 1 & 0.73 & 1 & 0.71 & 1 & 0.67 & 1 \\
\hline Hangzhou & 0.51 & 2 & 0.46 & 4 & 0.49 & 3 & 0.59 & 2 & 0.49 & 2 \\
\hline Nanchang & 0.49 & 3 & 0.50 & 3 & 0.48 & 4 & 0.56 & 3 & 0.44 & 3 \\
\hline Tianjin & 0.49 & 4 & 0.51 & 2 & 0.50 & 2 & 0.55 & 4 & 0.40 & 4 \\
\hline Baoding & 0.41 & 5 & 0.39 & 5 & 0.41 & 5 & 0.41 & 5 & 0.41 & 5 \\
\hline Average & 0.52 & $\mathrm{n} / \mathrm{a}$ & 0.52 & $\mathrm{n} / \mathrm{a}$ & 0.52 & $n / a$ & 0.56 & $\mathrm{n} / \mathrm{a}$ & 0.48 & $\mathrm{n} / \mathrm{a}$ \\
\hline
\end{tabular}

n/a not applicable

Sources: The data used to calculate the indices are from NBS (2011a-g, 2012a-g, 2013a-g, 2014a-g); Statistics Bureau of Shenzhen City (2011, 2012, 2013, 2014); Nanchang Municipal Statistics Bureau (2011, 2012, 2013, 2014); Tianjin Municipal Statistics Bureau (2011, 2012, 2013, 2014); Statistical Bureau of Baoding $(2011,2012,2013,2014)$.

It is also important to observe that Shenzhen's score has been declining over time, falling from 0.75 in 2010 to 0.68 in 2013. In contrast, Hangzhou's lowcarbon development has been improving over time, moving from fourth place in 2010 to second place in 2013. The scores for Nanchang and Tianjin have been fluctuating over time, but are consistently lower than the average. Baoding's ranking has been last for all four years and shows no apparent improvement.

In terms of geographic locations, Shenzhen and Hangzhou, ranking first and second, are in China's south-eastern coastal region. Nanchang, in third place, is in the central region, while Tianjin and Baoding, in fourth and last place, are in the north of the country. Therefore, the level of low-carbon development of Chinese cities presents an apparent declining trend from the cities in the south to the cities in the north. One reason could be the coal intensity of steel production in cities like Baoding in the northern region. However, the most important reason may be because the overall economic and social development levels in the south, especially in the south-eastern cities, are higher than those of northern cities. Cities in the south-eastern region also have more advantages in terms of technology, capital, human resources and city infrastructure development, which in turn facilitate rapid industrial restructuring and technological upgrading, especially in improving energy efficiency and reducing the emissions of high carbon dioxide-emitting industries. This also reveals that, in the process of pursuing city development, the 'low-carbon' development model is practical and necessary to achieve the goals of sustainable city development, including economic growth, good industrial structure, city construction and environmental protection. Therefore, 'low-carbon' is not only a goal but also the means by which to achieve sustainable development. 


\section{Evaluating the level of low-carbon city development by dimensions}

Tables 13.5-9 present the scores for low-carbon city development by the five dimensions for each of the five cities.

Table 13.5 Economic growth

\begin{tabular}{|l|r|r|r|r|r|r|r|r|r|r|}
\hline & \multicolumn{2}{|c|}{$\begin{array}{c}\text { Four-year } \\
\text { average }\end{array}$} & \multicolumn{2}{c|}{2010} & \multicolumn{2}{c|}{2011} & \multicolumn{2}{|c|}{2012} & \multicolumn{2}{c|}{2013} \\
\hline City & Score & Ranking & Score & Ranking & Score & Ranking & Score & Ranking & Score & Ranking \\
\hline Shenzhen & 0.15 & 1 & 0.15 & 1 & 0.15 & 1 & 0.16 & 1 & 0.17 & 1 \\
\hline Hangzhou & 0.14 & 2 & 0.14 & 2 & 0.15 & 2 & 0.13 & 2 & 0.13 & 2 \\
\hline Nanchang & 0.11 & 3 & 0.10 & 3 & 0.11 & 3 & 0.11 & 4 & 0.11 & 3 \\
\hline Tianjin & 0.08 & 4 & 0.07 & 4 & 0.06 & 4 & 0.12 & 3 & 0.07 & 4 \\
\hline Baoding & 0.01 & 5 & 0.02 & 5 & 0.01 & 5 & 0.01 & 5 & 0.01 & 5 \\
\hline Average & $\mathbf{0 . 5 2}$ & $\mathrm{n} / \mathrm{a}$ & $\mathbf{0 . 5 2}$ & $\mathrm{n} / \mathrm{a}$ & $\mathbf{0 . 5 2}$ & $\mathrm{n} / \mathrm{a}$ & $\mathbf{0 . 5 6}$ & $\mathrm{n} / \mathrm{a}$ & $\mathbf{0 . 4 8}$ & $\mathrm{n} / \mathrm{a}$ \\
\hline
\end{tabular}

Sources: NBS (2011a-g, 2012a-g, 2013a-g, 2014a-g); Statistics Bureau of Shenzhen City (2011, 2012, 2013, 2014); Nanchang Municipal Statistics Bureau (2011, 2012, 2013, 2014); Tianjin Municipal Statistics Bureau (2011, 2012, 2013, 2014); Statistical Bureau of Baoding (2011, 2012, 2013, 2014).

Table 13.6 Energy utilisation

\begin{tabular}{|l|r|r|r|r|r|r|r|r|r|r|}
\hline & \multicolumn{2}{|c|}{$\begin{array}{c}\text { Four-year } \\
\text { average }\end{array}$} & \multicolumn{2}{|c|}{2010} & \multicolumn{2}{c|}{2011} & \multicolumn{2}{|c|}{2012} & \multicolumn{2}{c|}{2013} \\
\hline City & Score & Ranking & Score & Ranking & Score & Ranking & Score & Ranking & Score & Ranking \\
\hline Shenzhen & 0.29 & 1 & 0.31 & 1 & 0.31 & 1 & 0.31 & 1 & 0.24 & 1 \\
\hline Nanchang & 0.18 & 2 & 0.20 & 2 & 0.16 & 2 & 0.21 & 3 & 0.15 & 3 \\
\hline Baoding & 0.16 & 3 & 0.14 & 4 & 0.12 & 5 & 0.21 & 4 & 0.15 & 2 \\
\hline Hangzhou & 0.15 & 4 & 0.13 & 5 & 0.13 & 4 & 0.22 & 2 & 0.12 & 4 \\
\hline Tianjin & 0.15 & 5 & 0.16 & 3 & 0.13 & 3 & 0.20 & 5 & 0.10 & 5 \\
\hline Average & $\mathbf{0 . 5 2}$ & $\mathrm{n} / \mathrm{a}$ & $\mathbf{0 . 5 2}$ & $\mathrm{n} / \mathrm{a}$ & $\mathbf{0 . 5 2}$ & $\mathrm{n} / \mathrm{a}$ & $\mathbf{0 . 5 6}$ & $\mathrm{n} / \mathrm{a}$ & $\mathbf{0 . 4 8}$ & $\mathrm{n} / \mathrm{a}$ \\
\hline
\end{tabular}

Sources: NBS (2011a-g, 2012a-g, 2013a-g, 2014a-g); Statistics Bureau of Shenzhen City (2011, 2012, 2013, 2014); Nanchang Municipal Statistics Bureau (2011, 2012, 2013, 2014); Tianjin Municipal Statistics Bureau (2011, 2012, 2013, 2014); Statistical Bureau of Baoding (2011, 2012, 2013, 2014). 
Table 13.7 Urban construction

\begin{tabular}{|l|r|r|r|r|r|r|r|r|r|r|}
\hline & \multicolumn{2}{|c|}{$\begin{array}{c}\text { Four-year } \\
\text { average }\end{array}$} & \multicolumn{2}{|c|}{2010} & \multicolumn{2}{c|}{2011} & \multicolumn{2}{|c|}{2012} & \multicolumn{2}{c|}{2013} \\
\hline City & Score & Ranking & Score & Ranking & Score & Ranking & Score & Ranking & Score & Ranking \\
\hline Shenzhen & 0.11 & 1 & 0.11 & 1 & 0.11 & 1 & 0.11 & 1 & 0.11 & 1 \\
\hline Hangzhou & 0.07 & 2 & 0.07 & 2 & 0.06 & 2 & 0.07 & 2 & 0.06 & 2 \\
\hline Nanchang & 0.06 & 3 & 0.06 & 3 & 0.06 & 3 & 0.06 & 3 & 0.06 & 3 \\
\hline Tianjin & 0.04 & 4 & 0.04 & 4 & 0.04 & 5 & 0.05 & 4 & 0.04 & 5 \\
\hline Baoding & 0.03 & 5 & 0.03 & 5 & 0.05 & 4 & 0.02 & 5 & 0.04 & 4 \\
\hline Average & 0.52 & $\mathrm{n} / \mathrm{a}$ & $\mathbf{0 . 5 2}$ & $\mathrm{n} / \mathrm{a}$ & $\mathbf{0 . 5 2}$ & $\mathrm{n} / \mathrm{a}$ & $\mathbf{0 . 5 6}$ & $\mathrm{n} / \mathrm{a}$ & 0.48 & $\mathrm{n} / \mathrm{a}$ \\
\hline
\end{tabular}

Sources: NBS (2011a-g, 2012a-g, 2013a-g, 2014a-g); Statistics Bureau of Shenzhen City (2011, 2012, 2013, 2014); Nanchang Municipal Statistics Bureau (2011, 2012, 2013, 2014); Tianjin Municipal Statistics Bureau (2011, 2012, 2013, 2014); Statistical Bureau of Baoding (2011, 2012, 2013, 2014).

\section{Table 13.8 Government support}

\begin{tabular}{|l|r|r|r|r|r|r|r|r|r|r|}
\hline & \multicolumn{2}{|c|}{$\begin{array}{c}\text { Four-year } \\
\text { average }\end{array}$} & \multicolumn{2}{|c|}{2010} & \multicolumn{2}{|c|}{2011} & \multicolumn{2}{|c|}{2012} & \multicolumn{2}{c|}{2013} \\
\hline City & Score & Ranking & Score & Ranking & Score & Ranking & Score & Ranking & Score & Ranking \\
\hline Hangzhou & 0.14 & 1 & 0.13 & 3 & 0.14 & 3 & 0.15 & 1 & 0.15 & 2 \\
\hline Shenzhen & 0.14 & 2 & 0.14 & 1 & 0.15 & 2 & 0.12 & 2 & 0.15 & 1 \\
\hline Nanchang & 0.13 & 3 & 0.13 & 2 & 0.15 & 1 & 0.12 & 3 & 0.12 & 3 \\
\hline Baoding & 0.12 & 4 & 0.11 & 4 & 0.13 & 4 & 0.09 & 4 & 0.12 & 4 \\
\hline Tianjin & 0.09 & 5 & 0.11 & 5 & 0.11 & 5 & 0.09 & 5 & 0.06 & 5 \\
\hline Average & 0.52 & $\mathrm{n} / \mathrm{a}$ & $\mathbf{0 . 5 2}$ & $\mathrm{n} / \mathrm{a}$ & $\mathbf{0 . 5 2}$ & $\mathrm{n} / \mathrm{a}$ & $\mathbf{0 . 5 6}$ & $\mathrm{n} / \mathrm{a}$ & $\mathbf{0 . 4 8}$ & $\mathrm{n} / \mathrm{a}$ \\
\hline
\end{tabular}

Sources: NBS (2011a-g, 2012a-g, 2013a-g, 2014a-g); Statistics Bureau of Shenzhen City (2011, 2012, 2013, 2014); Nanchang Municipal Statistics Bureau (2011, 2012, 2013, 2014); Tianjin Municipal Statistics Bureau (2011, 2012, 2013, 2014); Statistical Bureau of Baoding (2011, 2012, 2013, 2014).

\section{Table 13.9 Residential energy consumption}

\begin{tabular}{|l|r|r|r|r|r|r|r|r|r|r|}
\hline & \multicolumn{2}{|c|}{$\begin{array}{c}\text { Four-year } \\
\text { average }\end{array}$} & \multicolumn{2}{|c|}{2010} & \multicolumn{2}{c|}{2011} & \multicolumn{2}{|c|}{2012} & \multicolumn{2}{c|}{2013} \\
\hline City & Score & Ranking & Score & Ranking & Score & Ranking & Score & Ranking & Score & Ranking \\
\hline Baoding & 0.09 & 1 & 0.09 & 1 & 0.09 & 1 & 0.09 & 1 & 0.09 & 1 \\
\hline Tianjin & 0.07 & 2 & 0.07 & 2 & 0.08 & 2 & 0.08 & 2 & 0.07 & 2 \\
\hline Nanchang & 0.04 & 3 & 0.04 & 3 & 0.05 & 3 & 0.05 & 3 & 0.04 & 3 \\
\hline Hangzhou & 0.04 & 4 & 0.03 & 5 & 0.04 & 4 & 0.04 & 4 & 0.04 & 4 \\
\hline Shenzhen & 0.02 & 5 & 0.04 & 4 & 0.01 & 5 & 0.01 & 5 & 0.01 & 5 \\
\hline
\end{tabular}

Sources: NBS (2011a-g, 2012a-g, 2013a-g, 2014a-g); Statistics Bureau of Shenzhen City (2011, 2012 , 2013, 2014); Nanchang Municipal Statistics Bureau (2011, 2012, 2013, 2014); Tianjin Municipal Statistics Bureau (2011, 2012, 2013, 2014); Statistical Bureau of Baoding (2011, 2012, 2013, 2014). 
A summary of these results is provided, in descending order of levels of lowcarbon development.

\section{Shenzhen}

Shenzhen has the highest level of low-carbon development of the five sampled cities. It ranks first for economic growth, energy utilisation and urban construction, and second for government support. Shenzhen, however, ranks last in residential energy consumption, which is the weakest link in its lowcarbon development.

\section{Hangzhou}

Hangzhou's level of low-carbon development places it second among the five sampled cities. It is ranked first for government support, but comes in fourth for energy utilisation and residential energy consumption.

\section{Nanchang}

The level of Nanchang's low-carbon development ranks third among the five sampled cities. Of the five dimensions of low-carbon development, Nanchang has relatively low scores for economic growth, city construction and residential energy consumption, but relatively high scores for energy utilisation and government support. Across the period 2010-14, the rankings of the five dimensions of low-carbon development in relative terms are all declining over time.

\section{Tianjin}

Tianjin's overall level of low-carbon development is low despite the fact that the city has relatively high levels of economic development. Tianjin measures relatively well for economic growth and residential energy consumption, but scores lower for urban construction and government support.

\section{Baoding}

The overall level of Baoding's low-carbon development is very low, ranking it last among the five sampled cities. Of the five dimensions of low-carbon development used herein, Baoding has the highest score in residential energy consumption, but the lowest scores in economic growth and city construction. It also has relatively low scores for energy utilisation and government support. In other words, Baoding has a long way to go to achieve low-carbon development. 


\section{Conclusion and policy suggestions}

This chapter has used a multiple indicator system to evaluate the level of lowcarbon city development in five selected pilot low-carbon development cities in China. The evaluation model includes five dimensions: economic growth, energy utilisation, city construction, government support and residential consumption. We invited experts to allocate weights to each of the 17 indicators and calculated the score for each of the five dimensions and the total score for the LCCDI for the eight national pilot low-carbon cities for the period 2010-13. Based on the calculated scores, we evaluated the level of low-carbon city development for five selected cities. The main findings are as follows.

First, the low-carbon development and economic growth of a city do not form a 'zero-sum' relationship. 'Low-carbon' and 'development' can be achieved simultaneously. This study reveals that the levels of economic development and low-carbon development in the southern Chinese cities are higher than those in the central and northern cities. This implies that 'low-carbon' and 'development' can go hand-in-hand, and that China and other countries can achieve a 'winwin' situation for both environmental protection and economic development. Therefore, in the process of implementing new urbanisation, and promoting economic and social development, a low-carbon development model can serve as a way to save resources while also achieving economic growth, which offers China a feasible path forward.

Second, the overall level of low-carbon development of the five cities is not high, and has shown little apparent improvement over the period 2010-13. Among the five cities, only Shenzhen - one of China's most economically advanced citieshas a relatively high level of low-carbon development, with a score above 0.7, while the other four cities all present relatively low levels. This reveals that after a number of years' implementation of low-carbon development, including energy saving and emissions reduction policies and interventions promoted by the government, there is no apparent improvement in the level of low-carbon development in the national pilot low-carbon cities. This also implies that there is room for improvement in low-carbon development in Chinese cities.

Third, geographically, the level of low-carbon city development is higher in the south than in the north. Shenzhen and Hangzhou scored the highest, followed by Nanchang in the central region, while the northern cities of Tianjin and Baoding present much lower low-carbon development indicators.

Fourth, there is heterogeneity between the five cities across the selected five dimensions. For example, Shenzhen has the highest overall level of low-carbon development among the five cities, but it scores the lowest for residential consumption. Tianjin has a relatively low overall score, but scores relatively 
high for economic growth. Baoding has the lowest score for the overall level of low-carbon development, but has a relatively high score for energy utilisation and the highest score for residential consumption. This suggests that cities may increase the level of low-carbon city development more effectively by targeting the weakest link.

Based on these main findings, we offer several policy suggestions to help promote the future development of low-carbon cities in China.

First, energy saving and emissions reduction measures are the most important tasks for future low-carbon development and China's urbanisation program. The key to realising energy savings and reducing emissions is to increase the efficiency of energy utilisation, adjust the energy structure, encourage related innovation and adoption and increase utilisation of less carbon-intensive energy sources. On the one hand, renewable sources such as solar, wind and tidal energy are carbon-free and can directly reduce carbon dioxide emissions if they are substituted for non-renewable fossil fuel-based energy sources, which also produce serious environmental pollution. On the other hand, the key to increasing energy efficiency is to upgrade, develop and extend low-carbon technology in a time-efficient manner. Currently, low-carbon technologies in China include mainly solar energy to generate electricity (photovoltaics), carbon capture and storage technology, green lighting (light-emitting diodes), and so on (Wang 2011). However, because China started developing low-carbon technology relatively late, its overall level of such technology is relatively low. Therefore, China should adopt and incorporate advanced low-carbon technology from abroad. This would help not only to reduce carbon dioxide emissions, but also to push forward innovation and the development of renewable energy technology, energy saving and emissions reduction technology and clean coal technology.

Second, on the one hand, government can use subsidies, taxation and concessional financing to encourage enterprises through the research and development process or to introduce low-carbon technology and increase its application share in production and consumption. For high energy consumption industries such as transportation and construction, the government should further encourage enterprises to accelerate industrial structural adjustment and upgrading. On the other hand, government should strengthen institutions and laws governing the low-carbon economy-for example, by operationalising a carbon trading and carbon finance market; improving taxation relating to the development of the low-carbon economy; implementing low-carbon economy laws and regulations; and better regulating and governing the construction and development of low-carbon cities. 
Third, China should pay great attention to the development of strategic new industries, one of the main characteristics of which is low consumption of energy and resources. This is also among the targets for low-carbon development under the urbanisation policy. Of the seven strategic new industries promoted by the Chinese Government, ${ }^{3}$ energy saving and environmentally friendly industries, new energy industries and the new energy car industry directly reflect the goal of low-carbon development. Compared with traditional heavy manufacturing industries, the new-generation information and communication technology industry, biology industry, high-end equipment manufacturing industry and new materials industry are also resource-saving industries. As they develop, these strategic new industries will promote the upgrading of the local industrial structure and fundamentally change local economic development. From the perspective of low-carbon and sustainable development, developing strategic new industries provides a clear direction for the future development of Chinese cities.

Fourth, China should allow the market to allocate resources and promote lowcarbon development under the umbrella of new urbanisation. It is important to gradually establish market-oriented low-carbon mechanisms - for example, through developing carbon emissions trading rights and carbon finance. China has created carbon dioxide emission trading exchanges in Shenzhen, Tianjin, Guangzhou, Hubei and Chongqing, and the Beijing environment exchange and Shanghai environment and energy exchange. However, the carbon trading quantity of these exchanges remains very low compared with those of developed countries in Europe and North America. The operation mechanism also needs to be improved.

Fifth, raising public awareness of and encouraging low-carbon consumption are also important for low-carbon city development. Currently, residents' poor understanding of low-carbon behaviour is the weakest link in the low-carbon city development chain in China. It is little understood, for example, that lowcarbon consumption does not have to be synonymous with reductions in quality. It must be communicated effectively that low-carbon development can improve people's quality of life. It will take a relatively long time to increase awareness of low-carbon consumption and change traditional consumption behaviour. Government should therefore make great efforts to publicise the significance of low-carbon residential consumption and encourage the public to gradually adopt a low-carbon consumption lifestyle, thus contributing to low-carbon and sustainable city development.

3 The seven strategic new industries proposed by the Chinese Government are energy saving and environmentally friendly industries, new generation information and communication technology industries, biology industries, high-end equipment manufacturing industries, new energy industries, new materials industries and new energy car industries. 


\section{References}

Baeumler, A., Ijjasz-Vasquez, E. and Mehndiratta, S. (eds)(2012), Sustainable lowcarbon city development in China, Washington, DC: World Bank Publications.

Bao, J., Miao, Y. and Chen, F. (2008), Low carbon economy: Revolution in the way of human economic development, China Industrial Economics, 4: 153-160.

Carr, E., Wingard, P., Yorty, S., Thompson, M., Jensen, N. and Roberson, J. (2007), Applying DPSIR to sustainable development, International Journal of Sustainable Development \& World Ecology, 14(6): 543-555.

Casler, S. and Blair, P. (1997), Economic structure, fuel combustion, and pollution emissions, Ecological Economics, 22(1): 19-27.

Fan, Y., Liu, L., Wu, G. and Wei, Y. (2006), Analysing impact factors of $\mathrm{CO}_{2}$ emissions using the STIRPAT model, Environmental Impact Assessment Review, 26(4): 377-395.

Feliciano, M. and Prosperi, D. (2011), Planning for low carbon cities: Reflection on the case of Broward County, Florida, USA, Cities, 28(6): 505-516.

Gabrielsen, P. and Bosch, P. (2003), Environmental indicators: Typology and use in reporting, Copenhagen: EEA.

Golove, W. and Schipper, L. (1997), Restraining carbon emissions: Measuring energy use and efficiency in the USA, Energy Policy, 25(7): 803-812.

Gu, C., Hu, L., Zhang, X., Wang, X. and Guo, J. (2011), Climate change and urbanization in the Yangtze River Delta, Habitat International, 35(4): 544-552.

$\mathrm{Hu}$, B. (2013), On the new urbanisation path with six integrated dimensions, Guangming Daily, 28 June.

$\mathrm{Hu}, \mathrm{M}$. and Li, A. (2016), Between vision and reality: China low carbon city development, Financial Times [Chinese], 3 April. Available from: ftchinese. com/story/001066469?full=y.

Huang, H. (2011), The China environment yearbook. Volume 5. State of change: Environmental governance and citizens' rights, [Book review], China Review International, 18(2): 253-256.

Intergovernmental Panel on Climate Change (IPCC) (2006), IPCC guidelines for national greenhouse gas, London: Cambridge University Press.

Li, B. (2013), Governing urban climate change adaptation in China, Environment and Urbanization, 25(2): 413-427. 
Li, J. and Wang, X. (2012), Energy and climate policy in China's twelfth fiveyear plan: A paradigm shift, Energy Policy, 41: 519-528.

Li, X. and Pan, J. (2015), China green development index report 2012, New York: Springer.

Liu, Z. (2015), China's carbon emissions report 2015, Cambridge, Mass.: John F. Kennedy School of Government, Harvard University.

Nanchang Municipal Statistics Bureau(2011), Nanchang statistical yearbook 2011, Beijing: China Statistics Press.

Nanchang Municipal Statistics Bureau (2012), Nanchang statistical yearbook 2012, Beijing: China Statistics Press.

Nanchang Municipal Statistics Bureau (2013), Nanchang statistical yearbook 2013, Beijing: China Statistics Press.

Nanchang Municipal Statistics Bureau (2014), Nanchang statistical yearbook 2014, Beijing: China Statistics Press.

National Bureau of Statistics (NBS) (2011a), China city construction statistical yearbook 2011, Beijing: China Statistics Press.

National Bureau of Statistics (NBS) (2011b), China city statistical yearbook 2011, Beijing: China Statistics Press.

National Bureau of Statistics (NBS) (2011c), China energy statistical yearbook 2011, Beijing: China Statistics Press.

National Bureau of Statistics (NBS) (2011d), China statistical yearbook on environment 2011, Beijing: China Statistics Press.

National Bureau of Statistics (NBS) (2011e), China statistical yearbook 2011, Beijing: China Statistics Press.

National Bureau of Statistics (NBS) (2011f), Hangzhou statistical yearbook 2011, Beijing: China Statistics Press.

National Bureau of Statistics (NBS) (2011g), Statistical bulletin of national economic and social development 2011, Beijing: China Statistics Press.

National Bureau of Statistics (NBS) (2012a), China city construction statistical yearbook 2012, Beijing: China Statistics Press.

National Bureau of Statistics (NBS) (2012b), China city statistical yearbook 2012, Beijing: China Statistics Press. 
National Bureau of Statistics (NBS) (2012c), China energy statistical yearbook 2012, Beijing: China Statistics Press.

National Bureau of Statistics (NBS) (2012d), China statistical yearbook on environment 2012, Beijing: China Statistics Press.

National Bureau of Statistics (NBS) (2012e), China statistical yearbook 2012, Beijing: China Statistics Press.

National Bureau of Statistics (NBS) (2012f), Hangzhou statistical yearbook 2012, Beijing: China Statistics Press.

National Bureau of Statistics (NBS) (2012g), Statistical bulletin of national economic and social development 2012, Beijing: China Statistics Press.

National Bureau of Statistics (NBS) (2013a), China city construction statistical yearbook 2013, Beijing: China Statistics Press.

National Bureau of Statistics (NBS) (2013b), China city statistical yearbook 2013, Beijing: China Statistics Press.

National Bureau of Statistics (NBS) (2013c), China energy statistical yearbook 2013, Beijing: China Statistics Press.

National Bureau of Statistics (NBS) (2013d), China statistical yearbook on environment 2013, Beijing: China Statistics Press.

National Bureau of Statistics (NBS) (2013e), China statistical yearbook 2013, Beijing: China Statistics Press.

National Bureau of Statistics (NBS) (2013f), Hangzhou statistical yearbook 2013, Beijing: China Statistics Press.

National Bureau of Statistics (NBS) (2013g), Statistical bulletin of national economic and social development 2013, Beijing: China Statistics Press.

National Bureau of Statistics (NBS) (2014a), China city construction statistical yearbook 2014, Beijing: China Statistics Press.

National Bureau of Statistics (NBS) (2014b), China city statistical yearbook 2014, Beijing: China Statistics Press.

National Bureau of Statistics (NBS) (2014c), China energy statistical yearbook 2014, Beijing: China Statistics Press.

National Bureau of Statistics (NBS) (2014d), China statistical yearbook on environment 2014, Beijing: China Statistics Press. 
National Bureau of Statistics (NBS) (2014e), China statistical yearbook 2014, Beijing: China Statistics Press.

National Bureau of Statistics (NBS) (2014f), Hangzhou statistical yearbook 2014, Beijing: China Statistics Press.

National Bureau of Statistics (NBS) (2014g), Statistical bulletin of national economic and social development 2014, Beijing: China Statistics Press.

National Development and Reform Commission (NDRC) (2008), National standard of the People's Republic of China, GB/T 2589-2008, General principles for calculation of total production energy consumption, Beijing: NDRC.

National Development and Reform Commission (NDRC) (2010), Notice for carrying out low-carbon pilot schemes at provincial and city levels, Beijing: NDRC. Available from: gov.cn/zwgk/2010-08/10/content_1675733.htm.

National Development and Reform Commission (NDRC) (2012), Circular on the second batch of national pilot low-carbon provinces and lowcarbon cities, Beijing: NDRC. Available from: ccchina.gov.cn/nDetail. aspx?newsId $=28162 \&$ TId $=60$.

Pulselli, F., Coscieme, L., Neri, L., Regoli, A., Sutton, P., Lemmi, A. and Bastianoni, S. (2015), The world economy in a cube: A more rational structural representation of sustainability, Global Environmental Change, 35: 41-51.

Selden, T. and Song, D. (1994), Environmental quality and development: Is there a Kuznets curve for air pollution emissions?, Journal of Environmental Economics and Management, 27(2): 147-162.

Shao, C. and Ju, M. (2010), Studies of low-carbon city indicator system based on the DPSIR model, Ecological Economics, 10: 95-99.

Soytas, U. and Sari, R. (2009), Energy consumption, economic growth, and carbon emissions: Challenges faced by an EU candidate member, Ecological Economics, 68(6): 1667-1675.

Statistical Bureau of Baoding (2011), Baoding statistical yearbook 2011, Beijing: China Statistics Press.

Statistical Bureau of Baoding (2012), Baoding statistical yearbook 2012, Beijing: China Statistics Press.

Statistical Bureau of Baoding (2013), Baoding statistical yearbook 2013, Beijing: China Statistics Press. 
Statistical Bureau of Baoding (2014), Baoding statistical yearbook 2014, Beijing: China Statistics Press.

Statistics Bureau of Shenzhen City (2011), Shenzhen statistical yearbook 2011, Beijing: China Statistics Press.

Statistics Bureau of Shenzhen City (2012), Shenzhen statistical yearbook 2012, Beijing: China Statistics Press.

Statistics Bureau of Shenzhen City (2013), Shenzhen statistical yearbook 2013, Beijing: China Statistics Press.

Statistics Bureau of Shenzhen City (2014), Shenzhen statistical yearbook 2014, Beijing: China Statistics Press.

Stern, D. and Common, M. (2001), Is there an environmental Kuznets curve for sulfur?, Journal of Environmental Economics and Management, 41(2): 162-178.

Tianjin Municipal Statistics Bureau (2011), Tianjin statistical yearbook 2011, Beijing: China Statistics Press.

Tianjin Municipal Statistics Bureau (2012), Tianjin statistical yearbook 2012, Beijing: China Statistics Press.

Tianjin Municipal Statistics Bureau (2013), Tianjin statistical yearbook 2013, Beijing: China Statistics Press.

Tianjin Municipal Statistics Bureau (2014), Tianjin statistical yearbook 2014, Beijing: China Statistics Press.

Wang, H. (2013), Review of DPSIR framework, Guidance of Economic Research, 19: 4-5.

Wang, W. (2011), Studies on status, problem and development mode of China's low-carbon technology, China Soft Technology, 12: 84-91.

Weidema, B., Thrane, M., Christensen, P., Schmidt, J. and Løkke, S. (2008), Carbon footprint, Journal of Industrial Ecology, 12(1): 3-6.

York, R., Rosa, E. and Dietz, T. (2003), STIRPAT, IPAT and ImPACT: Analytic tools for unpacking the driving forces of environmental impacts, Ecological Economics, 46(3): 351-65.

Zhang, X. and Cheng, X. (2009), Energy consumption, carbon emissions, and economic growth in China, Ecological Economics, 68(10): 2706-2712. 
This text is taken from China's New Sources of Economic Growth: Reform, resources and climate change, Volume 1, edited by Ligang Song, Ross Garnaut, Cai Fang \& Lauren Johnston, published 2016 by ANU Press, The Australian National University, Canberra, Australia. 